$\mathbb{1}$ Nordic Council of Ministers

\title{
Baltic 2030 \\ Bumps on the Road
}

How the Baltic Sea States are performing on the SDGs 


\section{Baltic 2030: Bumps on the Road}

How the Baltic Sea States are performing on the SDGs

Sven Beyersdorff and Esben Lanthén

ANP 2018:783

ISBN 978-92-893-5655-8 (PRINT)

ISBN 978-92-893-5656-5 (PDF)

ISBN 978-92-893-5657-2 (EPUB)

http://dx.doi.org/10.6027/ANP2018-783

(c) Nordic Council of Ministers 2018 and Council of the Baltic Sea States 2018

Layout: Gitte Wejnold

Cover Photo: Unsplash.com

Print: Rosendahls

Printed in Denmark

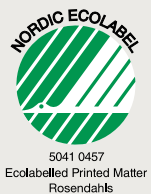

This publication has been commissioned by the Council of the Baltic Sea States and is published with financial support from the Nordic Council of Ministers.

\section{Co-operation in the Baltic Sea Region}

The Council of the Baltic Sea States is an overall political forum for regional cooperation. Consisting of 11 Member States (Denmark, Estonia, Finland, Germany, Iceland, Latvia, Lithuania, Norway, Poland, Russia \& Sweden), as well as a representative of the European Union, it supports a global perspective on regional problems. The CBSS work is guided by its three longterm priorities: Regional Identity, Sustainable \& Prosperous Region and Safe \& Secure Region.

\section{Council of the Baltic Sea States Secretariat}

Slussplan 9, P.O. Box 2010

SE-103 11 Stockholm

www.cbss.org

\section{Nordic co-operation}

Nordic co-operation is one of the world's most extensive forms of regional collaboration, involving Denmark, Finland, Iceland, Norway, Sweden, the Faroe Islands, Greenland, and Åland. Nordic co-operation has firm traditions in politics, the economy, and culture. It plays an important role in European and international collaboration, and aims at creating a strong Nordic community in a strong Europe.Nordic co-operation seeks to safeguard Nordic and regional interests and principles in the global community. Shared Nordic values help the region solidify its position as one of the world's most innovative and competitive.

\section{Nordic Council of Ministers \\ Nordens Hus \\ Ved Stranden 18 \\ DK-1061 Copenhagen K \\ www.norden.org}

Download and order Nordic publications from www.norden.org/nordpub 


\section{Baltic 2030 \\ Bumps on the Road}

How the Baltic Sea States are

performing on the SDGs

June 2018

(1) Nordic Council of Ministers
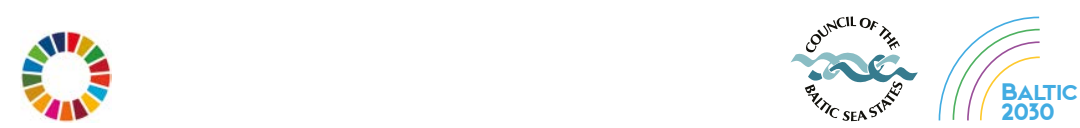



\section{FOREWORD}

This SDG implementation report Baltic 2030: Bumps on the Road - How the Baltic Sea States are performing on the SDGs was commissioned by the Council of the Baltic Sea States (CBSS), prepared by the sustainability advisory firm "Nordic Sustainability" and published in partnership with the Nordic Council of Ministers (NCM). The report aims to provide an overview of SDG implementation in the Baltic Sea Region to determine potential gaps and challenges, and to use this knowledge in strategy and prioritisation discussions involving the CBSS, the NCM and other actors engaged in macroregional collaboration in the Baltic Sea Region (BSR).

The views expressed in this paper are the authors' and do not necessarily reflect the opinions or policies of the Council of the Baltic Sea States or the Nordic Council of Ministers. Neither the authors nor the publishers can assume responsibility for any data errors in the original sources used for this report. 


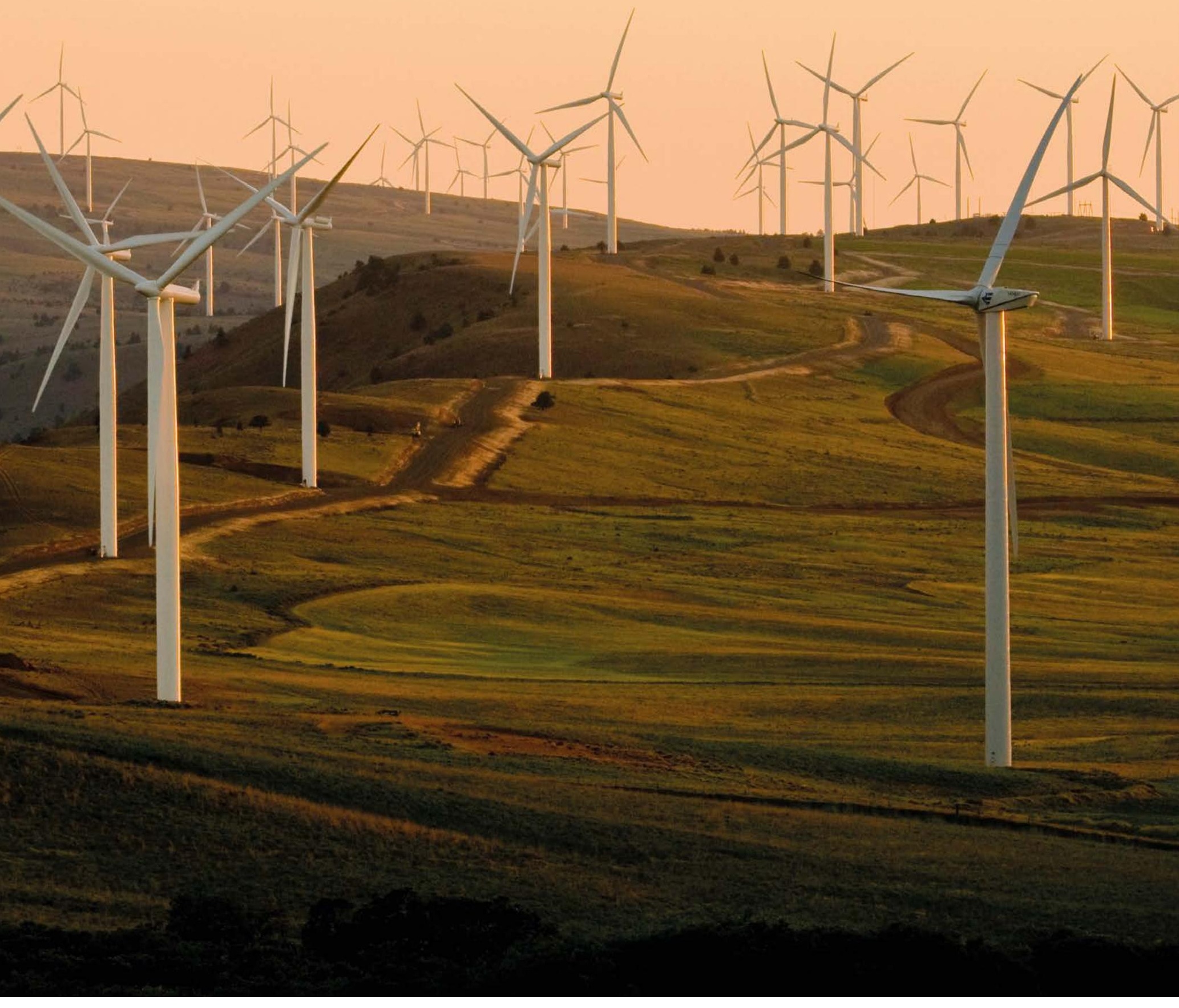




\title{
CONTENTS
}

\author{
9 Introduction
}

10 Executive Summary

12 Overview

SDG Performance across the Baltic Sea Region

14 Challenging Performance

SDG 12 - Responsible Consumption \& Production

16 Challenging Performance SDG 13 - Climate Action

18 Challenging Performance SDG 15 - Life on Land

20 Discrepant Performance SDG 8 - Decent Work and Economic Growth

22 Discrepant Performance SDG 11 - Sustainable Cities \& Communities

24 Avenues for Action

29 Methodology

33 References

34 Annex 1 Thresholds for indicator dashboard of five selected SDGs in absolute values

35 Annex 2

List of indicators for all SDGs for reference purposes 

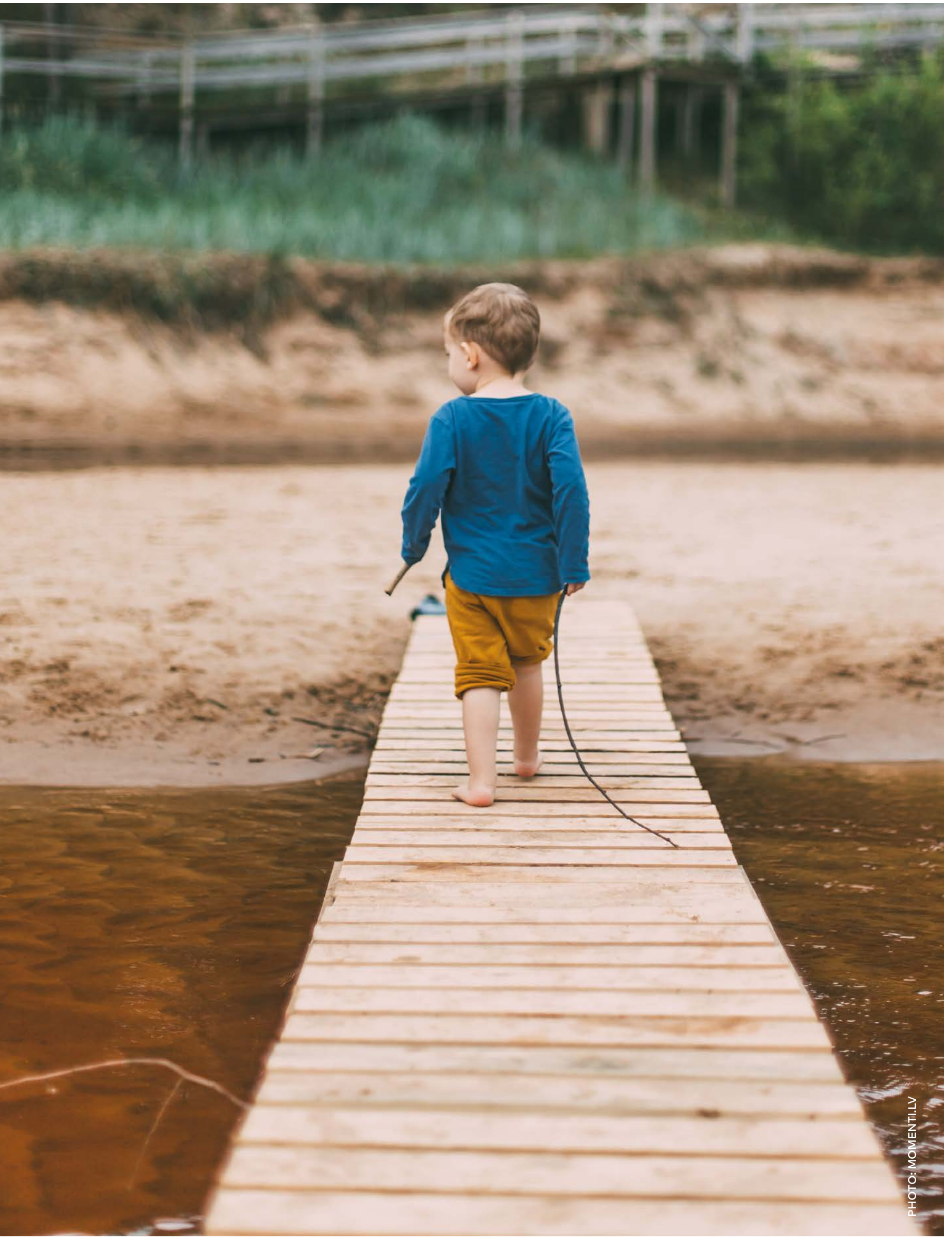


\section{INTRODUCTION}

The 2030 Agenda marked a point of transformative change in global cooperation for sustainable development. By creating and agreeing on the 17 Sustainable Development Goals (SDGs), the United Nations member states came together to implement sustainable development by 2030, and created a framework of targets and indicators to track progress along the way.

In June 2017 the Ministers of Foreign Affairs of the Council of the Baltic Sea States' (CBSS) member states endorsed the Baltic 2030 Action Plan, a vision for achieving sustainability in the Baltic Sea Region through transnational collaboration. In September 2017 the Nordic Council of Ministers (NCM) adopted the Generation 2030 Programme, which committed the NCM to focusing on the main challenges facing the Nordic countries in implementing the 2030 Agenda.

This report, Baltic 2030: Bumps on the Road, follows up on a similar Nordic report, Bumps on the Road to 2030, published by the NCM (2017a). Baltic 2030: Bumps on the Road uses updated data, and extends the analysis of critical SDGs to the whole Baltic Sea Region, including the Nordic countries. The report also reflects on joint actions the countries can take to overcome the common challenges. This report has been commissioned by the CBSS Expert Group on Sustainable Development (EGSD), and is published in collaboration with the NCM's Expert Group on Sustainable Development.

The aim of the report is to strategically guide activities of the CBSS and NCM and other actors in the BSR engaged in macroregional collaboration. It also seeks to support the prioritisation of actions based on where the largest impact towards achieving the SDGs can be made.

To support this, the authors of the report conclude by outlining seven Avenues for Action where macroregional collaboration could be particularly fruitful and where ideas are put forward for the work to attain the SDGs in the BSR. These avenues are intended as a tool for supporting the CBSS and NCM expert groups on sustainable development in identifying actions to be prioritised, as well as helping other actors at all levels across the BSR to work with the 2030 Agenda. 


\section{EXECUTIVE SUMMARY}

\section{Background}

The SDGs are ambitious goals that will require significant transformational shifts both in BSR countries and globally. This report shows that there are considerable implementation gaps, and strong engagement is needed across the BSR to implement the 2030 Agenda.

Analyses such as the one presented in this report can help guide prioritised actions and measurement of progress of ongoing initiatives. They also allow regional cooperation bodies, such as the CBSS and the NCM, as well as other actors at all levels of society in the BSR, to direct their activities towards fostering implementation across the region, enhancing cooperation and transferring knowledge where possible.

The analysis in this report is based on SDG performance data from the SDG Index and Dashboards Report 2017 (Bertelsmann Stiftung \& SDSN 2017). A total of 99 indicators for the 17 SDGs are compiled in the report, and new indicators, particularly on spillover effects between countries, are included in the 2017 edition as compared to the previous years (Bertelsmann Stiftung \& SDSN 2016). These 99 indicators may differ from UN indicators.

In relation to the total of 232 SDG indicators agreed upon by the UN member states, the coverage of 99 broadly corresponding indicators by the Bertelsmann report means that the range of available indicators and data for some SDGs may not always fully reflect all the targets covered by a particular SDG. This indicates a need for data improvement activities. Despite this, the SDG Index \& Dashboards report is the most complete and up-to-date data source on country SDG performance of the BSR countries currently available.

\section{Findings on Overall SDG Performance}

The report presents an overall assessment of the performance on all SDGs of the eleven countries in the BSR. The analysis shows that the countries are performing well on a global level, ranking at the top of the SDG Index. The average score of all countries across the region is comparable to countries such as the Netherlands and United Kingdom. However, challenges in implementation of the 2030 Agenda remain across most SDGs, with only SDG 1 (No Poverty) showing a good performance across the countries.

Based on the overall assessment, five SDGs are selected for analysis in the report. Three SGDs - SDG 12 (Responsible Consumption \& Production), SDG 13 (Climate Action), and SDG 15 (Life on Land) - are selected because they are particularly challenging across all countries in the region and can serve as focus areas for implementation efforts in the BSR. SDG 8 (Decent Work and Economic Growth) and SDG 11 (Sustainable Cities \& Communities) are chosen because countries in the region show discrepancies in performance and should, in many instances, be able to learn from each other when it comes to potential actions and solutions.

SDG 14 (Life Below Water) was not selected for in-depth analysis, despite the importance of the Baltic Sea in the region. This was to avoid duplication with the work of HELCOM, which has addressed challenges and risks relating to SDG 14 in its latest 'HELCOM State of the Baltic Sea' assessment (to be published in June 2018). 


\section{Findings on the Five SDGs in Focus}

Analysis of the three SGDs with challenging performance across the region identifies several indicators for each SDG where implementation of the 2030 Agenda is lagging. For SDG 12, the challenging performance can partially be attributed to e-waste generation and reactive nitrogen emitted during the production of goods. For SDG 13, energy-related $\mathrm{CO}_{2}$ emissions and the effective carbon rate of the countries in the BSR are a challenge. Finally, for SDG 15 the change in forest areas and imported biodiversity impacts are challenging for the region.

Examining the indicators regarding the two SDGs with discrepant performance can help us understand differences between BSR country implementation. For SDG 8, the discrepancy can mainly be seen with regards to both general and youth unemployment rates. For SDG 11, the discrepancy is particularly visible in the countries' levels of air pollution in cities, as well as the respective rent burden.

Despite good performance overall in the SDG Index and Dashboards Report as compared to other regions in the world, the BSR is currently far from sustainable. At indicator level, challenging performance can be identified across the board and on all SDGs. This should not be forgotten regardless of the more limited scope of this analysis. Indeed, the BSR countries should focus on all SDGs when they implement initiatives aimed at contributing to sustainable development in 2030.

\section{Avenues for Action}

Based on the analysis of SDG performance in the $B S R$, the authors of the report conclude by recommending seven avenues for action where macroregional collaboration can help facilitate the 2030 Agenda implementation and drive change. These are linked to the Priority Focus Areas (PFAs) of the Baltic 2030 Action Plan, and are aimed at supporting ongoing strategic initiatives:

- Avenue for action \#1| Work together and develop a common understanding of sustainable development in the BSR

- Avenue for action \#2 | Increase the pace of implementation of environmental goals

- Avenue for action \#3 | Address consumption through circularity and shifts to sustainable economies

- Avenue for action \#4 | Learn from the best on climate change

- Avenue for action \#5 | Use SDGs as a tool for avoiding spillover effects, also within the BSR

- Avenue for action \#6 | Support the youth to become the leaders for change

- Avenue for action \#7 | Strengthen joint data improvement activities 


\section{OVERVIEW: \\ SDG PERFORMANCE ACROSS THE BSR}

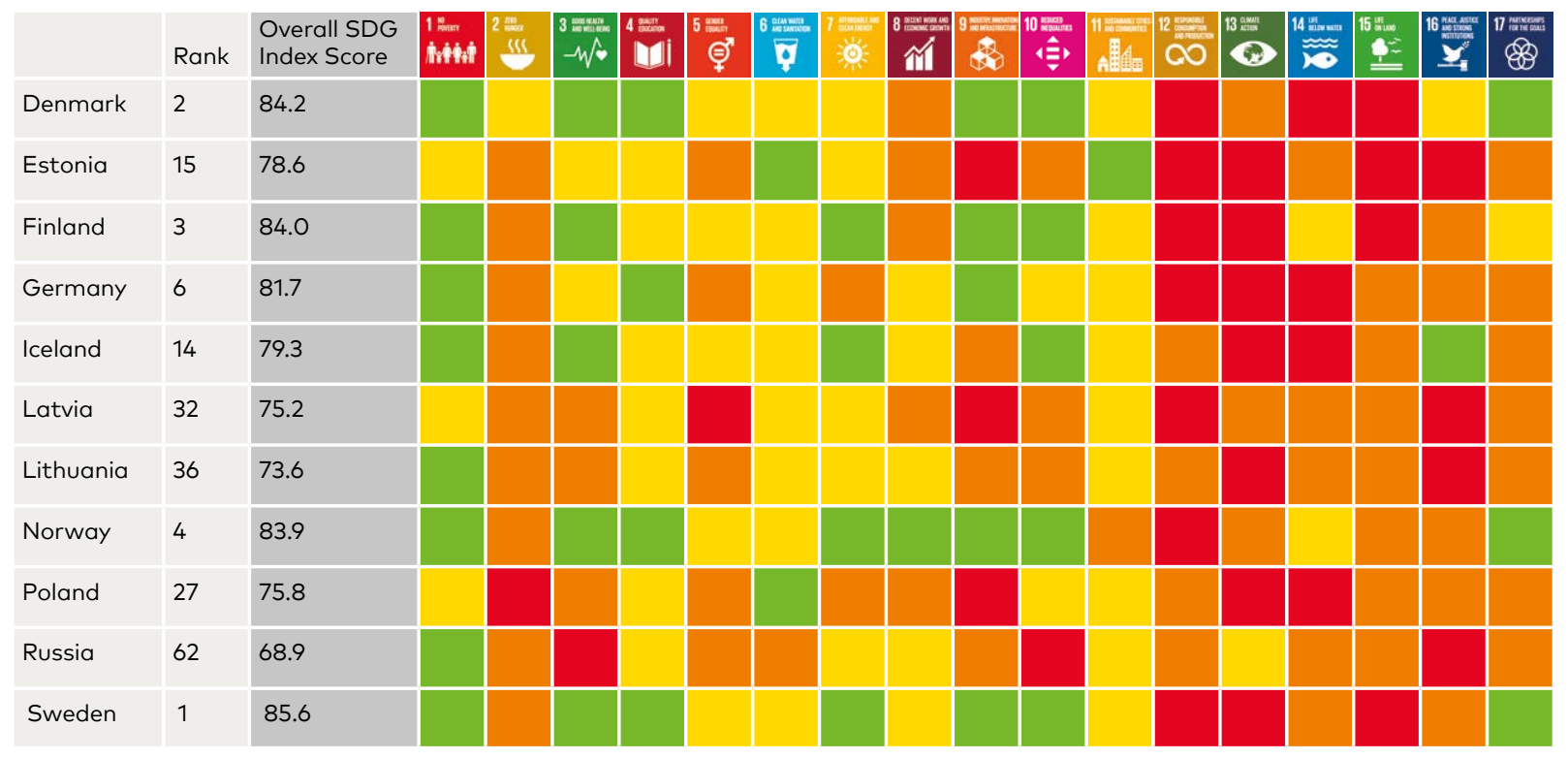

Scale

Figure 1: A green rating denotes SDG achievement, and is assigned to a country on a given SDG only if all the indicators under the goal are rated green. A red rating is applied only if the two worst-performing indicators score red. The thresholds for yellow and orange varies across the SDGs (Bertelsmann Stiftung \& SDSN 2017).

The BSR countries are generally performing well and rank highly on overall SDG performance globally. Five of the top six countries in the SDG Index and Dashboards ranking are part of this region and two more countries are in the top 15 . The average overall SDG Index score across the BSR countries is 79.1, ranking the region slightly lower than the Netherlands and slightly higher than the United Kingdom. The highest-ranking countries in the region overall are the Nordic countries and Germany, yet a closer look shows that performance varies greatly for each SDG.
In terms of overall country performance, many unsatisfactory levels of 2030 Agenda implementation are evident, with a high proportion of the countries' performances on the SDGs categorised as either red or orange rather than yellow or green. This is due to the ambitious nature of the SDGs and their indicators, but also because the SDG Index and Dashboards Report's assessment is deliberately harsh, to reflect the degree of change necessary for achieving the global goals. 
We can identify certain groupings in terms of performance across the different goals. SDG 1, No Poverty, is the only goal that seems to be almost achieved in the BSR, with most countries categorised as green and only three countries categorised as yellow - although challenges at indicator level still remain in the countries. Three goals (SDG $4,6,7)$ show an overall average performance with mostly green or yellow ratings, but many goals show quite poor performance (in descending order: 8, 3, $10,9,5,17,2,16,14,15,13,12)$.

It should also be noted that the performance of BSR countries is generally challenging on those SDGs that mainly focus on the environmental aspects of sustainable development, namely SDGs 7 \& 11-15, with approximately one-third of country values categorised as red. Many of these naturally also impact on other SDGs.

For this report, we have selected five SDGs to focus on. Three SDGs are selected due to challenging performance across the region, where most countries are categorised as red and none as green. For these SDGs, countries across the board are a long way from reaching the goals in 2030. Two additional SDGs are selected for their discrepant performance, where there are clear discrepancies that deserve a closer look. The five selected SDGs are:

\section{Challenging Performance:}

- SDG 12 - Responsible Consumption \& Production

- SDG 13 - Climate Action

- SDG 15 - Life on Land

\section{Discrepant Performance:}

- SDG 8 - Decent Work \& Economic Growth

- SDG 11 - Sustainable Cities \& Communities

This selection is not meant to diminish the importance of any of the other SDGs. As an example, SDG 14 (Life Below Water) has a similar number of countries categorised as red and could have been an interesting choice for analysis. However, SDG 14 is covered extensively by the work of HELCOM and we refer all readers to HELCOM's reports for more information on the state of the Baltic Sea (HELCOM 2017). 


\section{SDG 12 - RESPONSIBLE CONSUMPTION \& PRODUCTION}

Indicator Dashboard for Goal 12 - Responsible Consumption \& Production

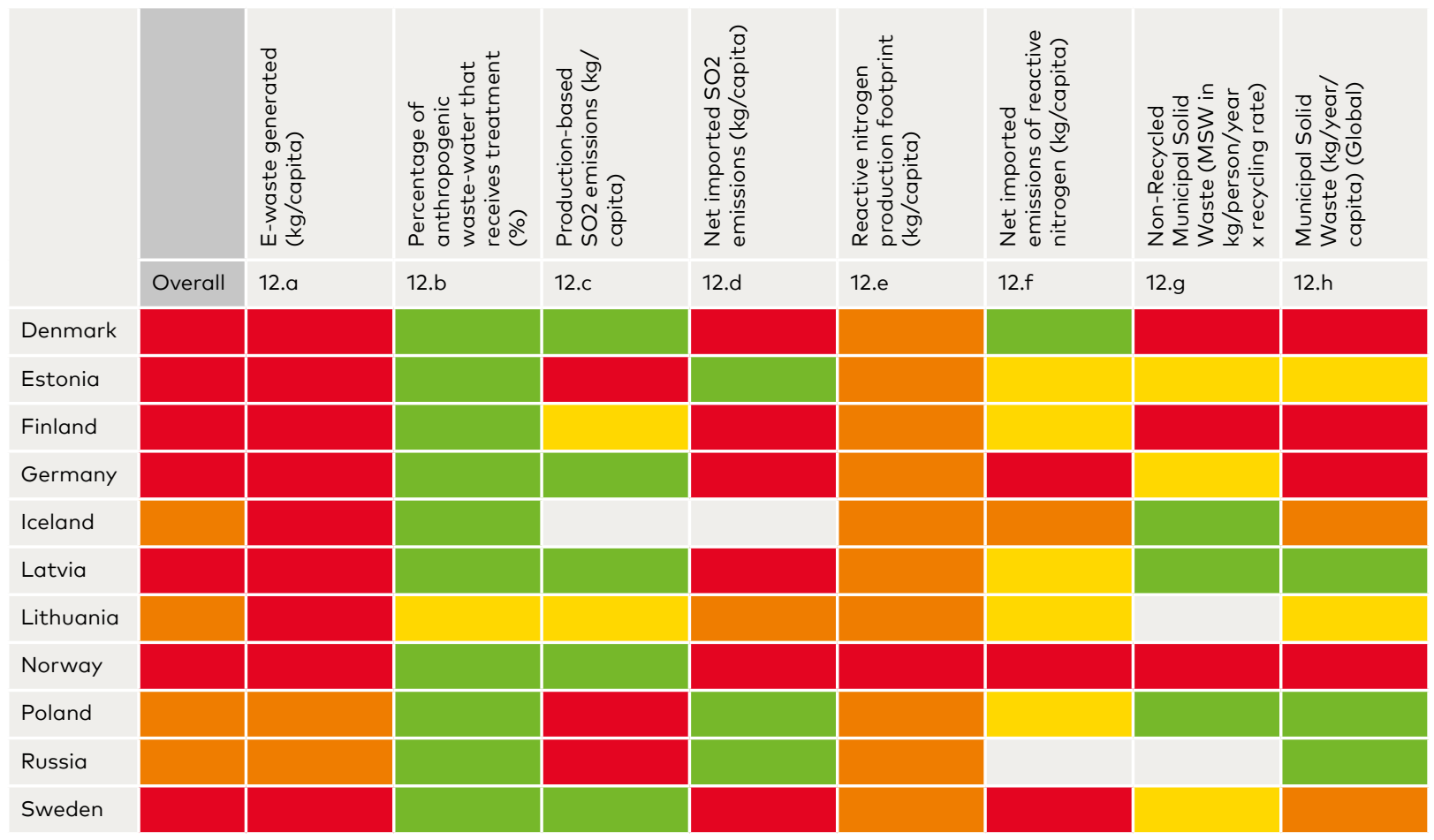

Figure 2: The green colour rating denotes the maximum that can be achieved for each variable or the threshold for achieving the SDG. The red colour denotes the value of the 2.5th percentile of the distribution between all countries in the SDG Index and Dashboards Report. Thresholds for the yellow and orange colours vary across indicators. All thresholds are listed in absolute values in Annex 1. Please note that the indicator numbering used in this report does not correspond to the official UN SDG indicator numbering. (Bertelsmann Stiftung \& SDSN 2017).

\section{Situation}

SDG 12, Responsible Production and Consumption, presents a significant challenge across the whole region, with all countries being categorised as either orange or red in terms of overall performance on this goal. The challenging performance on SDG 12 can largely be attributed to the BSR countries' performance on indicators 12. a and 12.e, reflecting chal- lenges on e-waste generation and reactive nitrogen emitted during the production of commodities.

Spillover effects with regard to $\mathrm{SO}_{2}$ emissions and reactive nitrogen also present a challenge, particularly for the Nordic countries and Germany, on their path towards more sustainable production and consumption. 


\section{At the indicator level}

It is clear that all countries are struggling to manage e-waste (12.a), although there are differences in performance between countries. Norway generates the most e-waste in the region, $28.3 \mathrm{~kg}$ per person annually. This is more than three times the amount that Russia produces, which has the least e-waste in the region at $8.7 \mathrm{~kg}$ per person annually.

Indicator 12.e concerns reactive nitrogen, which is often emitted to the atmosphere or water bodies during the production of commodities. This can be harmful to human health and the environment. Performance on this indicator is generally poor across the region, with Norway standing out with almost $25 \%$ higher levels of emissions per capita than the next BSR country in terms of performance, Denmark. Indicators 12.g and 12.h describe waste problems across the BSR, which are worst in the most developed countries.

As stated in the methodology section, indicators on spillover effects generally have a more negative effect on countries with higher GDP, namely the Nordic countries and Germany. On both the spillover indicators relating to $\mathrm{SO}_{2}$ emissions and reactive nitrogen, the performance of Norway, Sweden and Germany stands out as being particularly challenging. Denmark, surprisingly, is performing better on imported emissions of reactive nitrogen than on the production of reactive nitrogen.

\section{Implications \& perspectives}

SDG 12 assessment of the BSR countries shows clearly that implementation is still facing significant challenges across all indicators except for indicator 12.b, waste treatment, where performance of most countries is good. This calls for a range of efforts to encourage sustainable practices for the production and consumption of products in the region to achieve the 2030 Agenda objectives.

As an example, with the boom in consumer electronics, e-waste is considered to be one of the fastest growing waste streams in the EU, with growth rates of 3-5\% per year (Eurostat 2018). At the same time, despite the implementation of the WEEE1 Directive in Europe, which manages the end of life management of a wide range of electronics, collection rates for small electronics remain low (NCM 2017b). A range of approaches can help address the issue of e-waste, such as regulation or other initiatives to encourage recycling of electronics, more sustainable materials in production, or design for disassembly. These may also create new business opportunities in a more circular economy.

All countries in the BSR must intensify their efforts and work towards ensuring responsible consumption and production patterns in their economies and promote a greener and more circularity-based economy if SDG 12 is to be achieved by 2030 . 


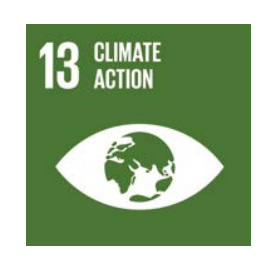

Indicator Dashboard for Goal 13 - Climate Action

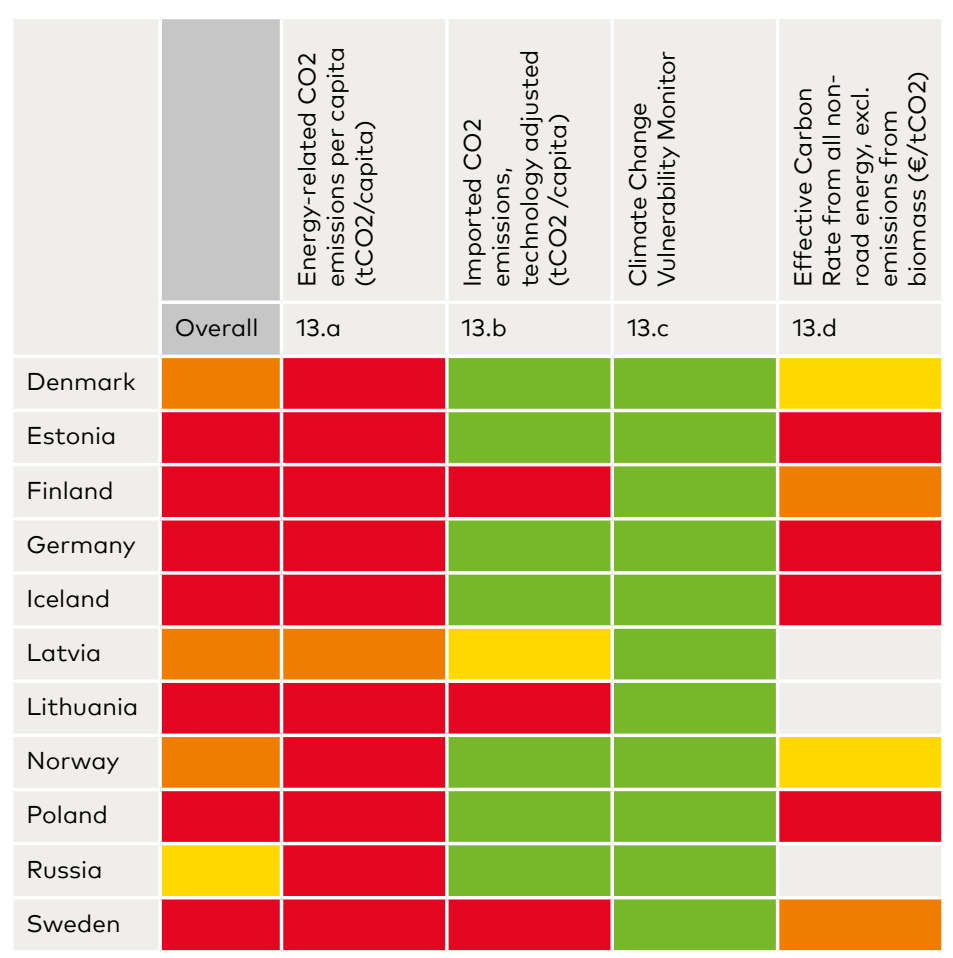

Figure 3: The green colour rating denotes the maximum that can be achieved for each variable or the threshold for achieving the SDG. The red colour denotes the value of the 2.5th percentile of the distribution between all countries in the SDG Index and Dashboards Report. Thresholds for the yellow and orange colours vary across indicators. All thresholds are listed in absolute values in Annex 1. Please note that the indicator numbering used in this report does not correspond to the official UN SDG indicator numbering. (Bertelsmann Stiftung \& SDSN 2017).

\section{Situation}

SDG 13, Climate Action, is characterised by its potentially significant negative impact on a number of SDGs if global warming is not brought to a halt. When assessing the indicators, the picture is relatively clear, with significant challenges across the region with regards to both energy-related $\mathrm{CO}_{2}$ emissions (indicator 13.a) and the effective carbon rate (indicator 13.d). Russia is the only country categorised as yellow in the overall rating of SDG 13, though this is also due to missing data for indicator 13.d.

\section{At the indicator level}

Indicator 13.a measures emissions of carbon dioxide per capita that arise from the consumption of 
energy. This includes emissions from the consumption of petroleum, natural gas and coal, as well as natural gas flaring. For SDG 13, this indicator has the poorest performance across the region. It is interesting to note that performance varies across the three Baltic countries, with Latvia and Lithuania having the lowest emissions per capita at 3.5 and 4.3 tons $\mathrm{CO}_{2}$ respectively. Estonia produces significantly more, 15.1 tons $\mathrm{CO}_{2}$ per capita, which is the highest across the region. According to the OECD (2017), Estonia needs to reduce its reliance on oil shale, currently providing $70 \%$ of the energy supply, to achieve a less carbon-intensive energy system and economy.

A mixed picture is also found for imported $\mathrm{CO}_{2}$ emissions that are measured by indicator 13.b, with highest levels in Finland, Lithuania, Sweden, and Latvia. Interestingly, for both indicator 13.a and 13.b, the performance is mixed across development levels in the region. This is testament to the different composition of the respective countries' energy systems, access to natural resources, imports of goods, and other factors critical to $\mathrm{CO}_{2}$ emission levels.

Despite missing data for three countries in the region, namely Latvia, Lithuania and Russia, the effective carbon rate indicator shows that the region is struggling with creating green growth. The indicator describes the ability of the region to decouple the economic output from $\mathrm{CO}_{2}$ emissions and, strikingly, the countries showing the best performance are also the countries with some of the strongest economies. Denmark holds a significant leadership position in the region on this indicator, $€ 67$ per ton of $\mathrm{CO}_{2}$ emitted, whereas Poland emits a ton of $\mathrm{CO}_{2}$ every time approximately $€ 12$ is added to the GDP.

\section{Implications \& Perspectives}

As a result of climate change, the BSR is warming, and it is warming faster than the global average. This can be seen, for example, in an expected decrease in snowfall of $75 \%$ and reduction of sea ice of $50-80 \%$ in the region within the next 100 years (HELCOM 2017). SDG 13 should therefore be a clear priority for BSR countries, but looking at the data across countries, we see that implementation is still lagging. The BSR countries' performance on the SDG 13 indicators shows that implementation initiatives in all countries should focus on reducing the use of fossil fuels and decoupling $\mathrm{CO}_{2}$ emissions from economic growth.

The challenges for this SDG are particularly troubling, as climate change cuts across all sectors and has potentially negative impacts on other SDGs. Finally, and on a positive note, all countries in the region are performing well on climate change vulnerability as measured on three main potential impacts of global warming: increase in weather-related disasters, sea level rise and loss of agricultural productivity. There is a clear difference between climate change vulnerability and resilience of the Nordic and Baltic countries, even though this gap seems to be diminishing, as described by the Notre Dame Global Adaptation Initiative's vulnerability and resilience readiness index (ND-GAIN 2016). 
Indicator Dashboard for Goal 15 - Life on Land

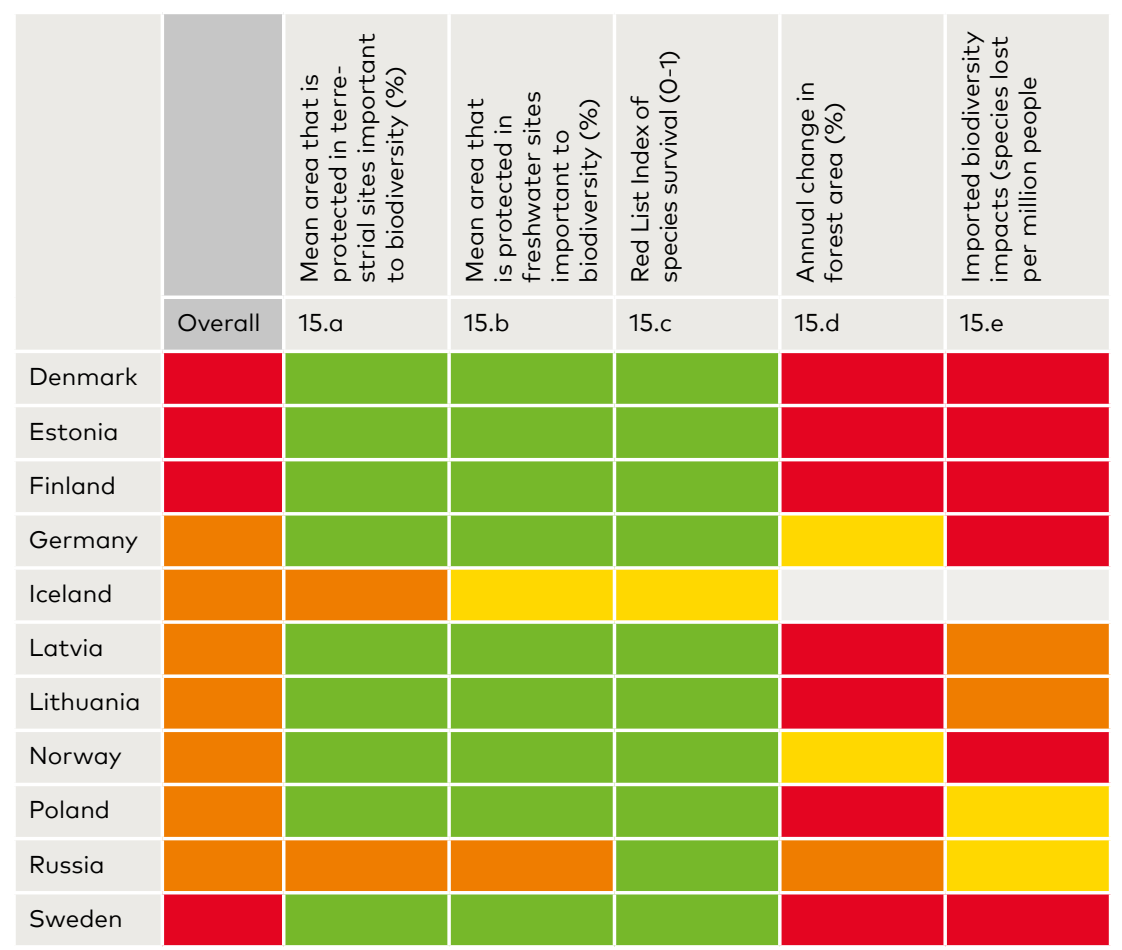

Figure 4: The green colour rating denotes the maximum that can be achieved for each variable or the threshold for achieving the SDG. The red colour denotes the value of the 2.5 th percentile of the distribution between all countries in the SDG Index and Dashboards Report. Thresholds for the yellow and orange colours vary across indicators. All thresholds are listed in absolute values in Annex 1. Please note that the indicator numbering used in this report does not correspond to the official UN SDG indicator numbering. (Bertelsmann Stiftung \& SDSN 2017).

\section{Situation}

On SDG 15, Life on Land, the region can largely be divided into two groups. All countries are struggling on this SDG, but particularly Denmark, Estonia, Finland and Sweden, whose overall rating on this goal is red. The situation is predominantly driven by poor performance on the annual change in forest areas (indicator 15.d) and imported biodiversity impacts (indicator 15.e). Most of the countries are performing well on the remaining three indicators.

\section{At the indicator level}

Indicator 15.e represents how the imported food crops of each country affect biodiversity, which is understood as the number of species lost in the production of the crop. This indicator therefore tells the story of whether the countries import food that is harmful to biodiversity in the origin countries. For this indicator, it is the Nordic countries and Germany that are most challenged in terms of performance, which seems to reflect research suggesting 
that more industrialised countries generally have a larger level of imported biodiversity impacts (The European Commission \& Chaudhary and Kastner 2016).

Indicator 15.d describes the total area of tree loss from 2000 to 2014, benchmarked against the country's tree cover baseline extent in 2000 . All countries in the region lost tree areas from 2000 to 2014, with Norway and Germany showing the smallest losses, $3.6 \%$ and $4.1 \%$ respectively. In the same timeframe, Latvia has lost as much as $13.2 \%$ of its total forest area.

It is worth noting that while Russia and Iceland are categorised as orange in the overall rating for this SDG, their performance compared to the rest of the region stands out with more challenges at indicator level. On indicator 15.a, all countries have more than $50 \%$ of their mean area protected in terrestrial sites important to biodiversity, whereas Iceland and Russia only have $18 \%$ and $27.2 \%$ respectively.

\section{Implications \& Perspectives}

While there are significant challenges relating to overall performance on SDG 15, the region as a whole is performing well on the indicators concerning protected areas and freshwater sites (indicator 15.a and 15.b), as well as on species survival (indicator 15.c). For most countries, this means that, in order to improve performance on SDG 15, they should focus implementation work on addressing the negative trend in annual forest change (indicator 15.d) and limit imports of crops associated with high levels of species loss (indicator 15.e). With regard to indicator 15.d, forestry is a sizeable industry across many of the BSR countries, which calls for increased work to implement sustainable forest management, together with the industry, to preserve existing forest areas.

For indicator 15.e, the negative biodiversity impacts of crop imports in developed countries largely stem from imports of crops from tropical areas in the world, where food production activities can lead to deforestation and associated loss of species (The European Commission 2016 \& Chaudhary and Kastner 2016). An obvious avenue for addressing this issue would be to reduce crop imports and use more domestic resources for crop production, but developed countries are often reliant on crop imports while many economies in tropical area countries depend on food exports. Interventions in exporting countries towards more sustainable food and biofuel production practices should also be seen as a way to lessen environmental impact locally and improve performance on this indicator in the BSR. 


\section{Indicator Dashboard for Goal 8 - Decent Work and Economic Growth}

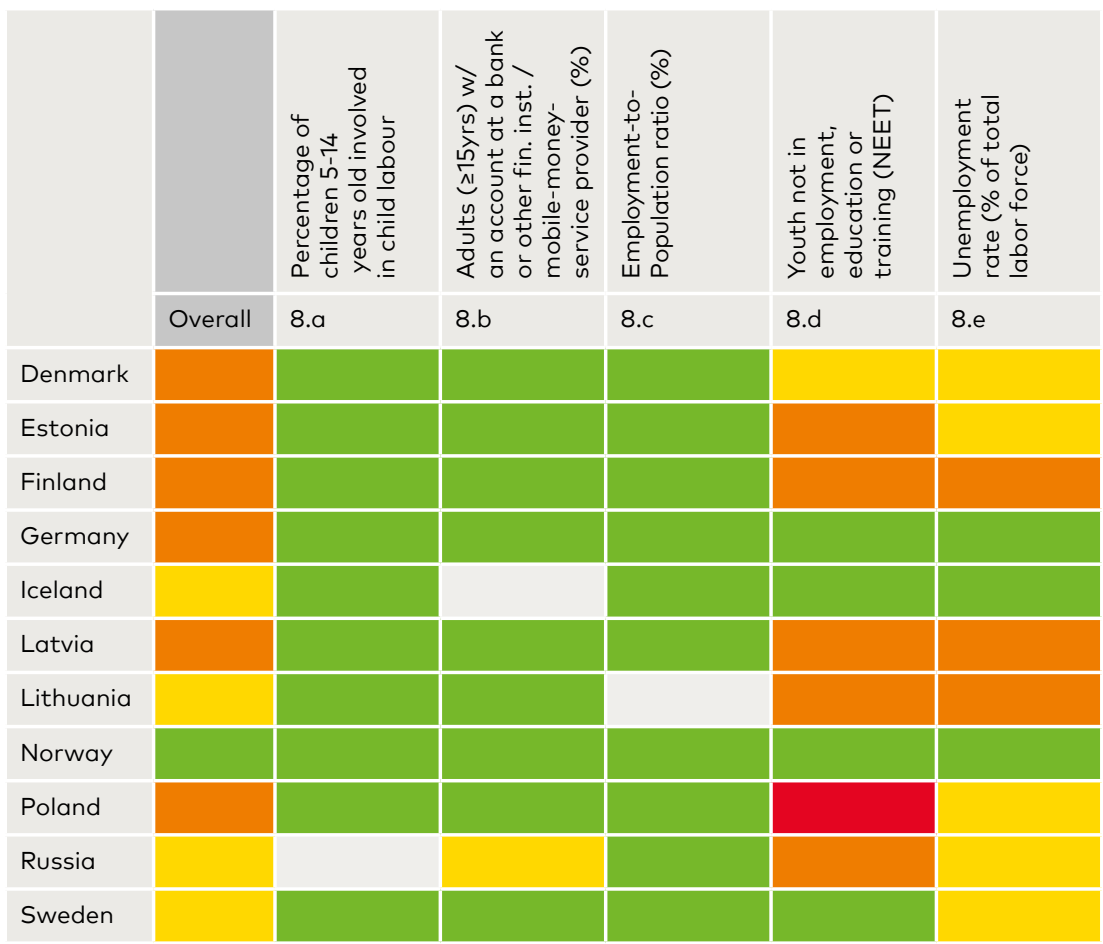

Figure 5: The green colour rating denotes the maximum that can be achieved for each variable or the threshold for achieving the SDG. The red colour denotes the value of the 2.5 th percentile of the distribution between all countries in the SDG Index and Dashboards Report. Thresholds for the yellow and orange colours vary across indicators. All thresholds are listed in absolute values in Annex 1. Please note that the indicator numbering used in this report does not correspond to the official UN SDG indicator numbering. (Bertelsmann Stiftung \& SDSN 2017). Data for one additional indicator which can be found in the Bertelsmann report, 'Adjusted Growth', was not included in this report due to concerns both on the indicator's transparency and on how it was constructed. Regardless of this, the individual ratings on this indicator still affect overall SDG ratings per country. Data for Russia on Indicator 8.c was provided by Rosstat, the Russian Federal State Statistics Service.

\section{Situation}

SDG 8, Decent Work and Economic Growth, was selected for this analysis because of the BSR countries' discrepant performance on this SDG. Despite overall performance in the region categorised as either yellow or orange, with only Norway as green, there are significant discrepancies when the performance is examined in detail at indicator level. In particular, unemployment and youth unemployment are a challenge for the region. 


\section{At the indicator level}

Significant discrepancies can be found regarding the unemployment rate of the total workforce, as shown in indicator 8.f, where three countries, Germany, Iceland, and Norway, are categorised as green, indicating less than $5 \%$ unemployment. Iceland takes the lead on this indicator in the region with only $3.8 \%$ unemployment. At the same time, Finland, Latvia, and Lithuania all have significantly higher levels of unemployment in their workforce at more than $9 \%$, which places them in the orange category for this indicator.

The discrepancies become even more apparent for youth unemployment, and the performance is generally poorer across the region than for indicator 8.e. All BSR countries show higher levels of unemployment for youth than for the workforce as a whole. It should be noted that Sweden manages to move into the green category with a youth unemployment rate of $9.1 \%$, despite this also being higher than the $7.1 \%$ unemployment across the workforce. Poland is struggling the most with employing its youth, and its $15.6 \%$ unemployment rate results in a red rating. Latvia, Lithuania and Finland also need to address youth unemployment, with rates only a few percent lower than Poland. It should also be noted that the BSR countries are mostly at or below the EU average for youth unemployment, according to a 2015 Union of the Baltic Cities study (UBC 2015).

\section{Implications \& Perspectives}

Analysis of the SDG 8 indicators shows clearly that countries in the BSR are at different levels in terms of implementation, which applies particularly for employment (as seen on indicator 8.e and 8.f). The good news for the region is that it is generally performing well on the remaining indicators relating to child labour, access to bank accounts, and employment to population ratio.

The SDG stands out in this analysis because of its more socio-economic focus than the other selected SDGs, which are more concerned with environmental sustainability. The focus of this SDG on ensuring productive employment and decent work for all is particularly evident with regard to youth employment. It is important to stress that initiatives to improve youth employment can have a major impact and generate substantial savings for society if successful (UBC 2015). The discrepancies between the countries on employment issues also point to a need for more macro-regional cooperation where possible, to integrate youth into the workforce and to confront the challenges of increasing workforce mobility more generally.

Finally, it should be noted that indicators discussed in relation to this SDG are largely dependent on economic trends, which may fluctuate over time. However, in the work towards achieving this SDG, the BSR countries should focus their efforts on the more structural issues of growth and employment. 


\section{SDG 11 - SUSTAINABLE CITIES \& COMMUNITIES}

\section{Indicator Dashboard for Goal 11 - Sustainable Cities \& Communities}

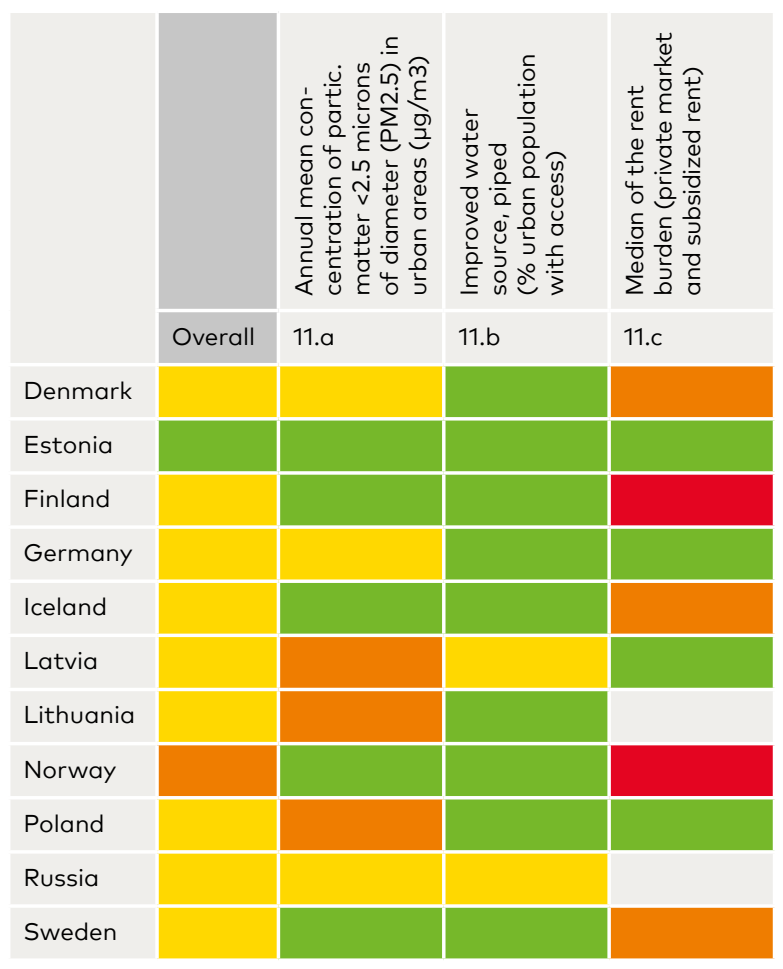

Figure 6: The green colour rating denotes the maximum that can be achieved for each variable or the threshold for achieving the SDG. The red colour denotes the value of the 2.5 th percentile of the distribution between all countries in the SDG Index and Dashboards Report. Thresholds for the yellow and orange colours vary across indicators. All thresholds are listed in absolute values in Annex 1. Please note that the indicator numbering used in this report does not correspond to the official UN SDG indicator numbering. (Bertelsmann Stiftung \& SDSN 2017).

\section{Situation}

On SDG 11, Sustainable Cities and Communities, discrepancies are visible particularly in the countries' levels of air pollution in cities (indicator 11.a) and the rent burden (indicator 11.b). Across the region, most countries are categorised as green on one or more indicators, while showing varying levels of implementation challenges on other indicators. This is the case for all countries apart from Estonia, which is quite clearly outperforming the rest of the region and is categorised as green across the board. 


\section{At the indicator level}

Indicator 11.a clearly shows how the countries are performing differently regarding the management of levels of air pollution in cities. The indicator is measured as the population-weighted mean annual concentration of PM2.5 for the urban population in each country. PM2.5 are suspended particles that can penetrate deep into the respiratory tract and can cause severe health damage. Latvia, Lithuania and Poland have the highest levels of air pollution, with Denmark, Germany, and Russia also lagging on this indicator. Perhaps most interestingly, Estonia has less air pollution than countries such as Germany and Denmark, with less than half the levels of particulate matter in the air. This is surprising, but could be an example of a spillover, since major oilshale power plants are located in the north-eastern border of the country, so emissions may often end up in Russia or Finland (Republic of Estonia 2017).

The discrepant performance is also seen on indicator 11.c, where three countries are categorised as green while four countries are either red or orange. The rent burden is measured as the percentage of a citizen's disposable income spent on housing, and averages $23.1 \%$ in the region. The Nordic countries have high rent burdens at around $30 \%$ of disposable incomes, with Norway hitting the highest level at $32.1 \%$. This is in sharp contrast to the $6.1 \%$ rent burden in Latvia, the lowest in the region. Despite data lacking for Lithuania and Russia, this indicator tells the story of citizens in the most developed economies using a larger share of their income on housing.

\section{Implications \& Perspectives}

By 2050, the world's urban population is expected to nearly double, making urbanisation a global megatrend. This trend is also seen in the Baltic Sea
Region, where many cities are growing (VASAB 2016). This development, paired with discrepancy in performance across the region, calls for learning between the countries and a better understanding of why individual countries stand out on these indicators. It should also be noted that, on indicator 11.b, the region is generally performing well, with over $90 \%$ of the population having access to water in all countries, with the exception of Latvia and Russia whose levels are slightly lower.

It is important to emphasise that SDG 11 and its indicators not only reflect the progress of the bustling metropolises and capitals of the region; the SDG also covers the sustainable development of smaller communities and towns, as well as supporting positive economic, social and environmental links between urban, semi-urban and rural areas. The indicators for SDG 11 cannot be achieved without a systemic view on implementing initiatives to address issues such as sustainable and low-emission transport and energy supply, spatial planning, resilience to climate change, and ensuring a supply of resources to industry and urban areas. This makes the implementation of SDG 11 a cross-sector action that will help achieve several other SDGs. A number of examples can be found across BSR cities, such as the 13 cities highlighted in the recent Union of Baltic Cities report on climate smart and sustainable cities (UBC 2017). 


\section{AVENUES FOR ACTION}

The key findings from this report are clear. All countries in the BSR need to work on all SDGs if the region is to realise the 2030 Agenda. Several SDGs stand out as particularly challenging, where the countries are far from implementing the 2030 Agenda. Decisive action is needed on these goals. This report has also identified SDGs where performance varies considerably across the countries in the region. Both types of SDGs, those with challenges across the board, as well as those where countries differ in their performance, provide ample scope for international cooperation.

Macroregional collaboration offers an opportunity for countries in the region to find solutions to common problems and learn from each other. Even where the BSR countries are diverse in their different contexts, targeted cooperation can still be extremely helpful in tackling common challenges. The sharing of best practices, as well as the joint development of new approaches and solutions, can make a big difference.
In the following section, the authors of this report recommend seven 'avenues for action' where macroregional collaboration in the work to attain the SDGs in the BSR may be particularly fruitful and provide ideas for how to move forward. These are directly linked to the six Priority Focus Areas (PFA) in the CBSS Baltic 2030 Action Plan, although not all Focus Areas are addressed with the same weight. The avenues for action are designed to strategically guide activities of the CBSS and other actors in the BSR engaged in macroregional collaboration. This also includes NCM and their member countries that are both part of the Nordic region and BSR.

These avenues for action were formulated on the basis of feedback from the workshop 'Transforming our Baltic Sea Region' organised by the Conference of Peripheral and Maritime Regions (CPMR) Baltic Sea Commission, Euroregion Baltic and the CBSS on 7 March 2018 in Stockholm, and the participants of the Swedish Institute's Baltic Leadership Programme in a workshop on 11 April 2018. The authors also received feedback from the CBSS and NCM Expert Groups on Sustainable Development. 


\section{Avenue for Action \#1 \\ Work together and develop a common under- standing of sustainable development in the BSR}

Towards fulfilling the Baltic 2030 Action Plan Priority Focus Area 1: Partnerships for Sustainable Development

The above analysis rests on an understanding of sustainable development unanimously agreed upon by all UN members. Despite the SDGs being a truly transformative development globally, such a widescale perspective also makes some of the nuances disappear, and sub-regional and local characteristics of sustainable development may not always be fully represented within the 2030 Agenda.

To facilitate SDG partnerships in the BSR, actors across all levels of governance in the region need to assume ownership and see the 2030 Agenda as their own agenda. Here, macroregional collaboration can help to develop a distinct BSR understanding of what sustainable development entails and how it should be monitored and achieved. Evidently, this will need to be aligned with the SGDs and focus attention on the global agenda rather than distract from it.

It also means that all actors (national/sub-

regional/local; urban/rural; private/public/NGO/ research; youth/other age groups; all genders) should understand why SDGs are important for them and how they can contribute. Governments across all levels need to translate global goals into regional and municipal actions, while national governments can help municipalities navigate what are still often perceived as competing agendas and ensuing trade-offs. For example, numerous representatives from regions and municipalities mentioned misalignments between the EU 2020 Strategy and the 2030 Agenda.

The CBSS and the NCM can involve national sustainable development coordinators, local and regional government representatives, as well as Policy Area/ Horizontal Action Coordinators of the EU Strategy for the Baltic Sea Region, to strengthen multi-level governance. Particular focus should be placed on stronger systems thinking and policy coherence, in an effort to harmonise sustainable development strategies across the various levels of governance and between policy areas.

\section{Avenue for Action \#2}

Increase the pace of implementation of environmental goals

Towards fulfilling the Baltic 2030 Action Plan Priority Focus Area 2: Transition to a Sustainable Economy

The SDGs relating to environmental aspects of sustainable development show a large gap in the implementation of the 2030 Agenda in the BSR. This concerns SDG 7 and SDGs 11-15, where approximately $1 / 3$ of country values across the BSR are categorised as red. The earlier analysis clearly demonstrates that the issues are complex, and performance on many indicators is troubling.

Fora in the region facilitate dialogue between countries, regions, cities, etc. on how these issues can be addressed, which shows that a strong infrastructure for macroregional collaboration already exists. 
However, to effectively advance the agenda, existing work needs to be aligned towards making an impact on the SDGs. The authors are of the opinion that the CBSS and the NCM are well-positioned to gather these stakeholders and ensure a coordinated effort towards SDG implementation.

\section{Avenue for Action \#3 \\ Address consumption and production through circularity and shifts to sustainable economies \\ Towards fulfilling the Baltic 2030 Action Plan Prior- ity Focus Area 2: Transition to a Sustainable Econ- omy}

Given that the BSR has one of the world's largest ecological footprints per capita, a crucial aspect of the environmental performance of the region lies in better management of consumption and production. Without action on this topic, and with continued development and economic growth, the BSR countries will use increasingly more resources and generate more waste. To address this, a multifaceted approach is needed to: 1) change consumption patterns, 2) reduce waste and manage waste streams towards greater circularity, and 3) improve efficiencies across the board.

The private sector can play its part, and we can see that many organisations in the region are already realising the potential of the circular economy, by designing business models and products that ensure a greater lifespan of resources. However, governments also need to supply the infrastructure and legislative framework that enable these changes to take place. For example, green procurement approaches need to be promoted and implemented much more widely across levels of governance. This is where macroregional collaboration can enable sharing of best practice.

\section{Avenue for Action \#4 Learn from the best on climate change}

\section{Towards fulfilling the Baltic 2030 Action Plan Prior- ity Focus Area 3: Climate Action}

Climate change represents one of the biggest challenges of our time and, if not addressed, will affect most other SDGs, making the 2030 Agenda almost impossible to implement. The transformations needed to mitigate climate change, as well as improve adaptation and resilience, require new solutions and signify times of great disruption and far-reaching changes regarding the way we structure our societies and economies.

These disruptions present opportunities where countries can spearhead developments together, experiment with new solutions, and learn from each other on how to implement existing solutions in this area. Several of the BSR countries have shown international best practice with policies on climate adaptation and mitigation. Further integration of governmental departments across the BSR working with climate change could be a key component of spreading learning and progress across the region. 


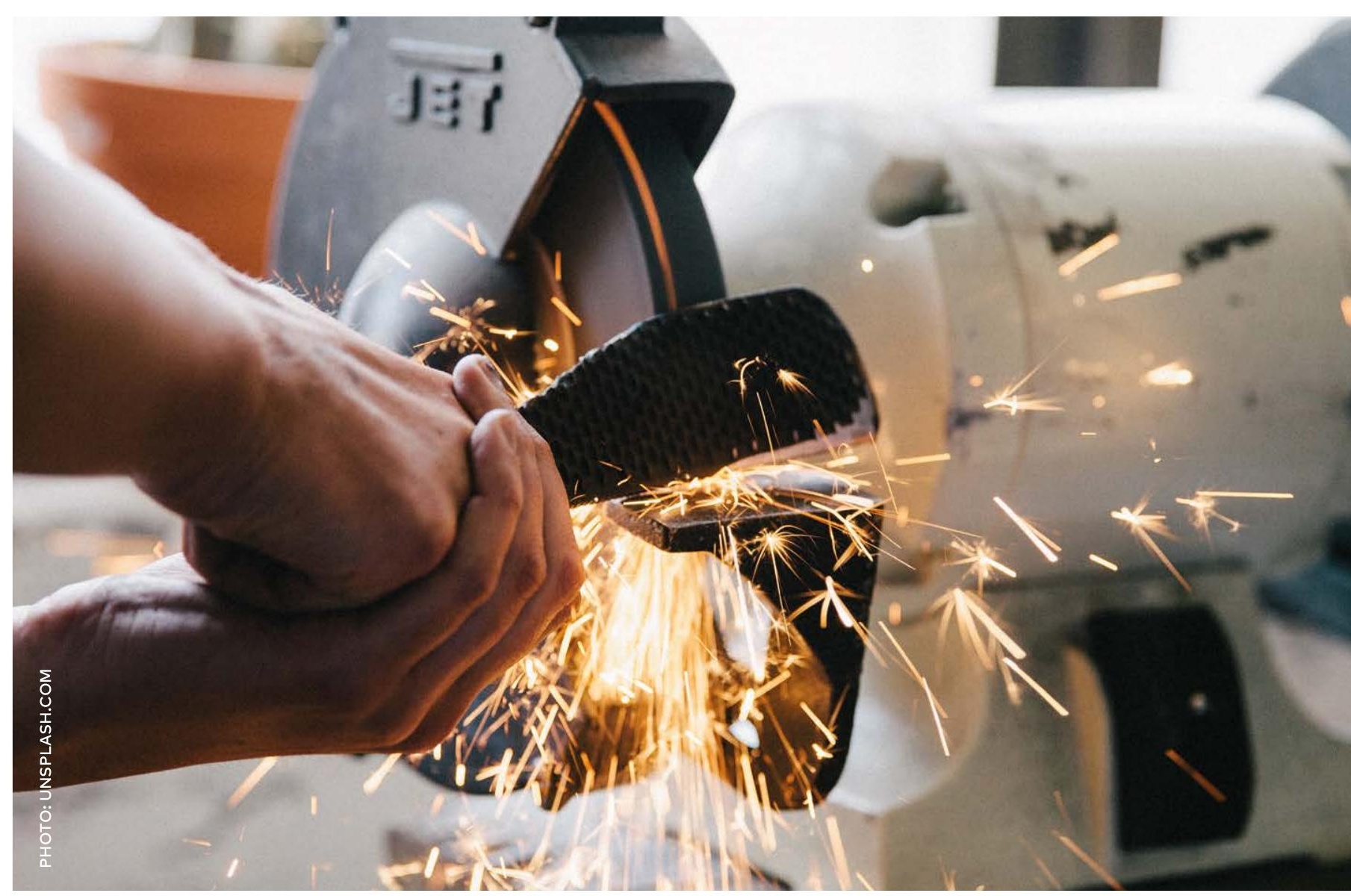

\section{Avenue for Action \#5 \\ Use SDGs as a tool for avoiding spillover effects, also within the BSR}

Towards fulfilling the Baltic 2030 Action Plan Priority Focus Area 5: Creating Sustainable and Resilient Cities

The 2017 edition of the SDG Index and Dashboards Report places additional weight on spillover effects when assessing sustainable development performance. This highlights areas where the BSR has negative effects either on other countries outside the region or internally between countries, for example regarding natural resource imports or goods manufacturing. As a region, this highlights a responsibility to both reduce these spillovers at home and across the region, as well as - where possible - support other actors (at local level within the region, externally with other countries, etc.).

The BSR should examine where it is best equipped to act. For example, the CBSS could set up a pilot project within the BSR to improve understanding of these effects and establish partnerships with other regions in the world to assist SDG implementation. Here, macroregional collaboration is an obvious stage for constructive dialogues on how countries in the region limit their negative spillovers, both internally and externally to their neighbours. Exchange between all stakeholders, including sub-national and local governments, parliamentarians, civil society, the private sector, professionals and practitioners, and the scientific and academic community, will be vital if this is to be achieved. 


\section{Avenue for Action \#6 \\ Support the youth to become the leaders for change}

Towards fulfilling the Baltic 2030 Action Plan Priority Focus Area 6: Quality Education and Lifelong Learning for All

Engaging young people and getting their support in driving the 2030 Agenda will be instrumental across all the issue areas. A particular example could be consumption patterns, where the younger generations play a key role. Fortunately, millennials seem to be inclined to base consumption choices on sustainability concerns. This is the group that can generate the most change by passing on altered consumption behaviours to the next generation.

This calls for macroregional collaboration in the BSR to continuously engage with young people to help shape mindsets and jointly work to change the status quo. Naturally, this is not meant to distract from the responsibility of those currently in positions of power to act as role models in positively inspiring others.

Education initiatives across governmental levels on SDGs could help people and societal groups use a common language, as well as promote the goals more generally. Intergenerational dialogue, co-learning and lifelong learning need to play a key part of such capacity-building work.

\section{Avenue for action \#7 \\ Strengthen joint data improvement activities}

Towards fulfilling the Baltic 2030 Action Plan Priority Focus Area 1: Partnerships for Sustainable Development

The region can greatly benefit from aligning efforts to jointly improve data and reporting on SDGrelated indicators - perhaps in cooperation with the Bertelsmann Stiftung and the Sustainable Solutions Development Network - where this is not already done. The aim should be to cover a wider base of indicators and thereby create a more comprehensive picture of the region's progress towards SDG achievement.

National governments should jointly work on improving data at EU level, as well as specifically target areas that the countries wish to focus on. A possibility would be to initiate regular meetings between the statistics offices of the BSR countries.

Besides extending the available data, translating or breaking down data from the national level to the municipal and regional level should also be in focus, since it is actors on these levels that often bring about change. Helping lower governance levels assess the impact of their work towards SDGs is also highly relevant. 


\section{METHODOLOGY}

\begin{abstract}
Approach
The analysis presented in this report provides an overall picture of how BSR countries are performing in relation to all 17 SDGs. Based on this, five SDGs (three with challenging performance across all countries in the region, and two with discrepant performance between countries) are selected for more in-depth analysis. The focus on discrepant SDGs in this report is aimed at identifying areas where the countries can ideally learn from each other and collaborate.
\end{abstract}

In the analysis of the five selected SDGs, the report looks in depth at the specific indicators relating to overall SDG implementation. Here, selected indicators are described and analysed to illustrate the performance of the countries in the BSR in relation to the SDGs on a more detailed level.

\section{Sources of Data}

The analysis is mainly based on data from the SDG Index and Dashboards Report 2017, published by Bertelsmann Stiftung and the SDSN. The SDG Index and Dashboards Report is currently the most comprehensive data source that includes data on all SDGs for all BSR countries. Where relevant, the report also draws on other sources of information and data to provide context and guide action.

\section{Indicators Covered}

The SDG Index and Dashboards Report has compiled data on 99 indicators relating to the 17 SDGs. Compared to the total number of 232 SDG indicators agreed upon by the UN, this means that, for some SDGs, the range of available indicators and data will not fully reflect the progress towards a particular SDG and only inadequately cover some of the targets linked to that SDG. Further improvements in data and reporting are needed, and stakeholders are working hard to progress in this area. Those working with a particular SDG should compare the indicators in this report with the official UN targets and indicators of that SDG to ensure all relevant aspects are covered.

\section{SDG Index Scoring}

As the name suggests, the SDG Index and Dashboards Report includes both an index score and a dashboard rating. The index score expresses a country's performance from lowest $(0)$ to highest (100) at indicator and SDG level, and is used to rank the countries.

\section{SDG Dashboard Ratings}

The dashboard rates a country's performance at indicator and SDG level using a four-tiered colour rating - green, yellow, orange and red. More detailed information can be found in the report (Bertelsmann Stiftung \& SDSN 2017, p. 47).

At the SDG level, the basis for the colour rating is as follows:

- Green rating on the SDG Dashboard denotes that the SDG is achieved, and is assigned to a country only if all the indicators under the SDG are rated green

- Red rating is applied only if the two worstperforming indicators score red

- Thresholds between yellow and orange are based on the average of the two variables on which a country's performance achieved the lowest index 


\section{New indicators and spillover effects}

In its 2017 report, the SDG Index and Dashboards Report includes additional refinements of indicators and the addition of work on spillover effects that were lacking in previous editions. Spillovers are adverse effects of one country on another (though they may also appear locally/regionally), impacting that country's ability to achieve the SDGs (e.g. high consumption levels, bank secrecy \& tax havens, weapons exports). A more detailed colour rating, with four colours instead of three, was introduced in the 2017 edition. This means that a comparison of country performance between this report and the NCM's Bumps on the Road to 2030 report is not possible, as this report was based on the 2016 indicators.

The addition of spillover indicators in the SDG Index and Dashboards Report primarily affects the performance of high-income countries negatively. The data on the spillover indicators shows that high-income countries tend to generate negative SDG spillover effects for developing countries. The performance of BSR countries should therefore be affected negatively by the introduction of spillover effects.
Of the new indicators for the 2017 edition of the SDG Index and Dashboards Report, nine relate to the five SDGs selected for in-depth analysis in this report.

\section{New indicators:}

- SDG 12: E-waste generated (kg/capita)

- SDG 12: Production-based $\mathrm{SO}_{2}$ emissions (kg/capita)

- SDG 12: Nitrogen production footprint (kg/capita)

- SDG 13: Effective Carbon Rate $\left(€ / \mathrm{tCO}_{2}\right)$

- SDG 15: Freshwater sites, mean protected area (\%)

\section{New spillover indicators:}

- SDG 12: Net imported $\mathrm{SO}_{2}$ emissions (kg/capita)

- SDG 12: Net imported emissions of reactive nitrogen ( $\mathrm{kg} / \mathrm{capita}$ )

- SDG 13: Imported $\mathrm{CO}_{2}$ emissions, technology-adjusted ( $\mathrm{tCO}_{2}$ /capita)

- SDG 15: Imported biodiversity impacts (species lost per million people) score. The indicator values were first rescaled from 0 to 3, where 0 corresponds to the lower boundary, 1 to the value of the threshold between red and orange ('red threshold'), 2 to the value of the threshold between yellow and green ('green threshold'), and 3 to the upper boundary. For all indicators, the yellow/orange threshold was set as the value halfway between the red and green thresholds.

At the indicator level, the basis for the colour ratings is as follows:
- The boundary for the green colour rating is the maximum that can be achieved for each variable or the threshold for achieving the SDG The lower boundary for the red colour is the value of the 2.5th percentile of the distribution between the countries

- Thresholds for the yellow and orange colour ratings are established for each indicator by the authors of the SDG Index and Dashboards Report in consultation with experts. Absolute valves for the thresholds of all indicators relating to the selected SGDs are listed in Annex 1 


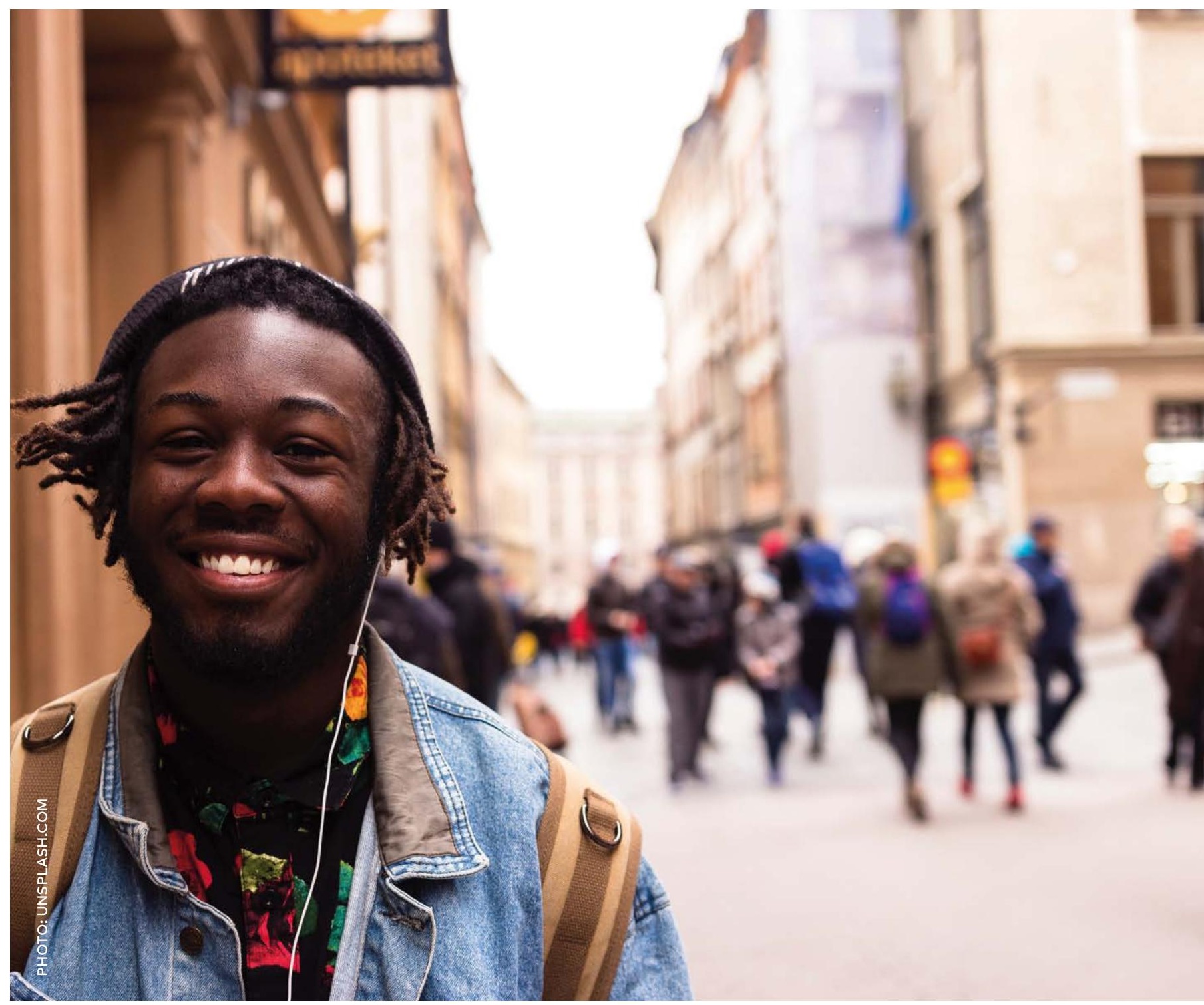

- In addition to the colour rating described above, this report includes a grey colour where data is missing on an indicator for one of the BSR countries. The colour ratings for each indicator were taken from the country profiles in the SDG Index and Dashboards Report, but in some cases (for example, SDG 8), data is available from the report's underlying data sheet that is not featured in the report itself. We added this data where possible to make the picture as complete as possible.

\section{Use of OECD data}

The SDG Index and Dashboards Report includes an OECD country index and dashboard with additional

available indicators. For this report, we added the OECD country indicators to obtain the most comprehensive perspective of BSR country performance on the SDGs. For these indicators, data for Russia and Lithuania is not available.

Lastly, it should be noted that there may be discrepancies between the internationally reported data used by the SDG Index and Dashboards Report and data from national statistics offices. Differences may occur where data originates from differing reporting periods or has been compiled by World Bank or UN organisations in certain ways to ensure consistency. 


\section{REFERENCES}

Bertelsmann Stiftung \& SDSN 2016: Sachs, J., SchmidtTraub, G., Kroll, C., Durand-Delacre, D. \& Teksoz, K. (2016). SDG Index and Dashboards - Global Report. New York: Bertelsmann Stiftung and Sustainable Development Solutions Network (SDSN).

Bertelsmann Stiftung \& SDSN 2017: Sachs, J., SchmidtTraub, G., Kroll, C., Durand-Delacre, D. and Teksoz, K. (2017). SDG Index and Dashboards Report 2017. New York: Bertelsmann Stiftung and Sustainable Development Solutions Network (SDSN).

CBSS 2017: Council of the Baltic Sea States (2017). Realizing the Vision: The Baltic 2030 Action Plan. Stockholm Sweden: Council of the Baltic Sea States (CBSS).

Chaudhary and Kastner 2016: Chaudhary, A. and Kastner, T. (2016). Land use biodiversity impacts embodied in international food trade. Global Environmental Change, 38: 195-204.

Eurostat 2018: Waste electrical and electronic equipment (weee). Accessed on January 29, 2018, at: http://ec. europa.eu/eurostat/web/waste/key-waste-streams/ weee

Helcom 2017: The Baltic Marine Environment Protection Commission: Measuring progress for the same targets in the Baltic Sea. The Baltic Marine Environment Protection Commission (Helcom).

NCM 2017a: Esben Alslund-Lanthén and Martin Larsen. Bumps on the Road to 2030. Copenhagen: The Nordic Council of Ministers (NCM).

NCM 2017b: David Watson, Anja Charlotte Gylling, Naoko Tojo, Harald Throne-Holst, Bjørn Baver and Leonidas Milios (2017). Circular Business Models in the Mobile Phone Industry. Copenhagen: The Nordic Council of Ministers (NCM).
ND-GAIN 2016: University of Notre Dame Global Adaptation Index (2016). ND-GAIN Country Index Accessed on February 16, 2018, at: https://gain.nd.edu/ our-work/country-index/.

OECD 2017: The Organisation for Economic Co-operation and Development (2017). Environmental Performance Reviews: Estonia 2017. Paris: OECD Publishing. Republic of Estonia 2017: Estonian Informative Inventory Report 1990-2015, Submitted under the Convention on Long-Range Transboundary Air Pollution. Tallinn: Environment Agency. Available on March 1 at: http:// www.keskkonnaagentuur.ee/sites/default/files/ estonia_iir_2017.pdf

The European Commission 2016: The hidden biodiversity impacts of global crop production and trade. Available on January 292018 at: http://ec.europa.eu/environment/ integration/research/newsalert/pdf/hidden_biodiversity impacts_of_global_crop_production_and_trade_461na2_ en.pdf

UBC 2015: The Union of the Baltic Cities (2015). UBC Task Force on Youth Employment and Well-Being. FINAL REPORT: The Good, The Bad and The Next Practices. Turku: Union of the Baltic Cities Secretariat.

UBC 2017: The Union of the Baltic Cities (2017). Baltic cities bulletin: Sustainable and climate-smart Baltic sea region cities. Gdańsk: Union of the Baltic Cities Secretariat.

VASAB 2016: Jānis Turlajs, Iveta Druva Druvaskalne, and Visvaldis Valtenbergs (2016). Development of Cities in the Baltic Sea Region, Latvia: HESPI and Jana seta Map Publishers Ltd. 


\section{ANNEX 1}

\section{THRESHOLDS FOR INDICATOR DASHBOARD OF FIVE SELECTED SDGS IN ABSOLUTE VALUES}

The table shows the thresholds for the indicators of the five selected SDGs in absolute values. We refer readers to the Bertelsmann Stiftung's SDG Index \& Dashboards report for further information on methodology and colour ratings.

\begin{tabular}{|c|c|c|c|c|c|}
\hline SDG & Indicator & $\begin{array}{l}\text { Colourbands } \\
\text { Green }\end{array}$ & Yellow & Orange & Red \\
\hline 8 & $\begin{array}{l}\text { 8.(x): Adjusted GDP Growth (\%) [not included in report] } \\
\text { 8.a: Percentage of children 5-14 years old involved in } \\
\text { child labour } \\
\text { 8.b: Adults ( } 15 \text { years and older) with an account at } \\
\text { a bank or other financial institution or with a } \\
\text { mobile-moneyservice provider (\%) } \\
\text { 8.c: Employment-to-Population ratio (\%) } \\
\text { 8.d: Youth not in employment, education or training } \\
\text { (NEET) } \\
\text { 8.e: Unemployment rate (\% total labor force) }\end{array}$ & $\begin{array}{l}>=0 \% \\
<=2 \% \\
>=80 \% \\
>=60 \% \\
<=10 \% \\
<=5 \%\end{array}$ & $\begin{array}{l}0 \%>x>=-1 \% \\
2 \%<x<=6 \% \\
80 \%>x>=65 \% \\
60 \%>x>=55 \% \\
10 \%<x<=12.5 \% \\
5 \%<x<=7.5 \%\end{array}$ & $\begin{array}{l}-1 \%>x>=-2 \% \\
6 \%<x<=10 \% \\
65 \%>x>=50 \% \\
55 \%>x>=50 \% \\
12.5 \%<x<=15 \% \\
7.5 \%<x<=10 \%\end{array}$ & $\begin{array}{l}<-2 \% \\
>10 \% \\
<50 \% \\
<50 \% \\
>15 \% \\
>10 \%\end{array}$ \\
\hline 11 & $\begin{array}{l}\text { 11.a: Annual mean concentration of particulate matter } \\
\text { of less than } 2.5 \text { microns of diameter (PM2.5) in urban } \\
\text { areas ( } \mu \mathrm{g} / \mathrm{m} 3 \text { ) } \\
\text { 11.b: Improved water source, piped (\% urban population } \\
\text { with access) } \\
\text { 11.c: Median of the rent burden (private market and } \\
\text { subsidized rent) as a share of disposable income }(\%)\end{array}$ & $\begin{array}{l}<=10 \\
>=98 \% \\
<=20 \%\end{array}$ & $\begin{array}{l}10<x<=17.5 \\
98 \%>x>=86.5 \% \\
20 \%<x<=25 \%\end{array}$ & $\begin{array}{l}17.5<x<=25 \\
86.5 \%>x>=75 \% \\
25 \%<x<=30 \%\end{array}$ & $\begin{array}{l}>25 \\
<75 \% \\
>30 \%\end{array}$ \\
\hline 12 & $\begin{array}{l}\text { 12.a: E-waste generated (kg/capita) } \\
\text { 12.b: Percentage of anthropogenic wastewater that } \\
\text { receives treatment (\%) } \\
\text { 12.c: Production-based } \mathrm{SO}_{2} \text { emissions (kg/capita) } \\
\text { 12.d: Net imported } \mathrm{SO}_{2} \text { emissions (kg/capita) } \\
\text { 12.e: Reactive nitrogen production footprint (kg/capita) } \\
\text { 12.f: Net imported emissions of reactive nitrogen (kg/ } \\
\text { capita) } \\
\text { 12.g: Non-Recycled Municipal Solid Waste (MSW in kg/ } \\
\text { person/year times recycling rate) } \\
\text { 12.h: Municipal Solid Waste (kg/year/capita) }\end{array}$ & $\begin{array}{l}<=5 \\
>=50 \% \\
<=10 \\
<=1 \\
<=8 \\
<=1.5 \\
<=1 \\
<=1\end{array}$ & $\begin{array}{l}5<x<=7.5 \\
50 \%>x>=32.5 \% \\
10<x<=20 \\
1<x<=8 \\
8<x<=29 \\
1.5<x<=75.75 \\
1<x<=1.25 \\
1<x<=1.5\end{array}$ & $\begin{array}{l}7.5<x<=10 \\
32.5 \%>x>=15 \% \\
20<x<=30 \\
8<x<=15 \\
29<x<=50 \\
75.75<x<=150 \\
1.25<x<=1.5 \\
1.5<x<=2\end{array}$ & $\begin{array}{l}>10 \\
<15 \% \\
>30 \\
>15 \\
>50 \\
>150 \\
>1.5 \\
>2\end{array}$ \\
\hline 13 & $\begin{array}{l}\text { 13.a: Energy-related } \mathrm{CO}_{2} \text { emissions per capita }\left(\mathrm{tCO}_{2} /\right. \\
\text { capita) } \\
\text { 13.b: Imported } \mathrm{CO}_{2} \text { emissions, technology- adjusted } \\
\text { ( } \mathrm{tC \textrm {O } _ { 2 }} / \text { capita) } \\
\text { 13.c: } \text { Climate Change Vulnerability Index } \\
\text { 13.d: Effective Carbon Rate from all non-road energy, } \\
\text { excluding emissions from biomass }\left(€ / \mathrm{tCO}_{2}\right)\end{array}$ & $\begin{array}{l}<=2 \\
<=0.5 \\
<=0.1 \% \\
>=70\end{array}$ & $\begin{array}{l}2<x<=3 \\
0.5<x<=0.75 \\
0.1 \%<x<=0.15 \% \\
70>x>=50\end{array}$ & $\begin{array}{l}3<x<=4 \\
0.75<x<=1 \\
0.15 \%<x<=0.2 \% \\
50>x>=30\end{array}$ & $\begin{array}{l}>4 \\
>1 \\
>0.2 \% \\
<30\end{array}$ \\
\hline 15 & $\begin{array}{l}\text { 15.a: Mean area that is protected in terrestrial sites } \\
\text { important to biodiversity (\%) } \\
\text { 15.b: Mean area that is protected in freshwater sites } \\
\text { important to biodiversity (\%) } \\
\text { 15.c: Red List Index of species survival ( } 0-1) \\
\text { 15.d: Annual change in forest area (\%) } \\
\text { 15.e: Imported biodiversity impacts (species lost per } \\
\text { million people) }\end{array}$ & $\begin{array}{l}>=50 \% \\
>=50 \% \\
>=0.9 \\
<=3 \% \\
<=0.1\end{array}$ & $\begin{array}{l}50 \%>x>=30 \% \\
50 \%>x>=30 \% \\
0.9>x>=0.85 \\
3 \%<x<=4.5 \% \\
0.1<x<=0.225\end{array}$ & $\begin{array}{l}30 \%>x>=10 \% \\
30 \%>x>=10 \% \\
0.85>x>=0.8 \\
4.5 \%<x<=6 \% \\
0.225<x<=0.35\end{array}$ & $\begin{array}{l}<10 \% \\
<10 \% \\
<0.8 \\
>6 \% \\
>0.35\end{array}$ \\
\hline
\end{tabular}




\section{LIST OF INDICATORS FOR ALL SDGS FOR REFERENCE PURPOSES}

The table shows all indicators covered by the Bertelsmann Stiftung's SDG Index Report in 2017. Indicators marked * are only included in the augmented SDG Index for OECD countries used for this report.

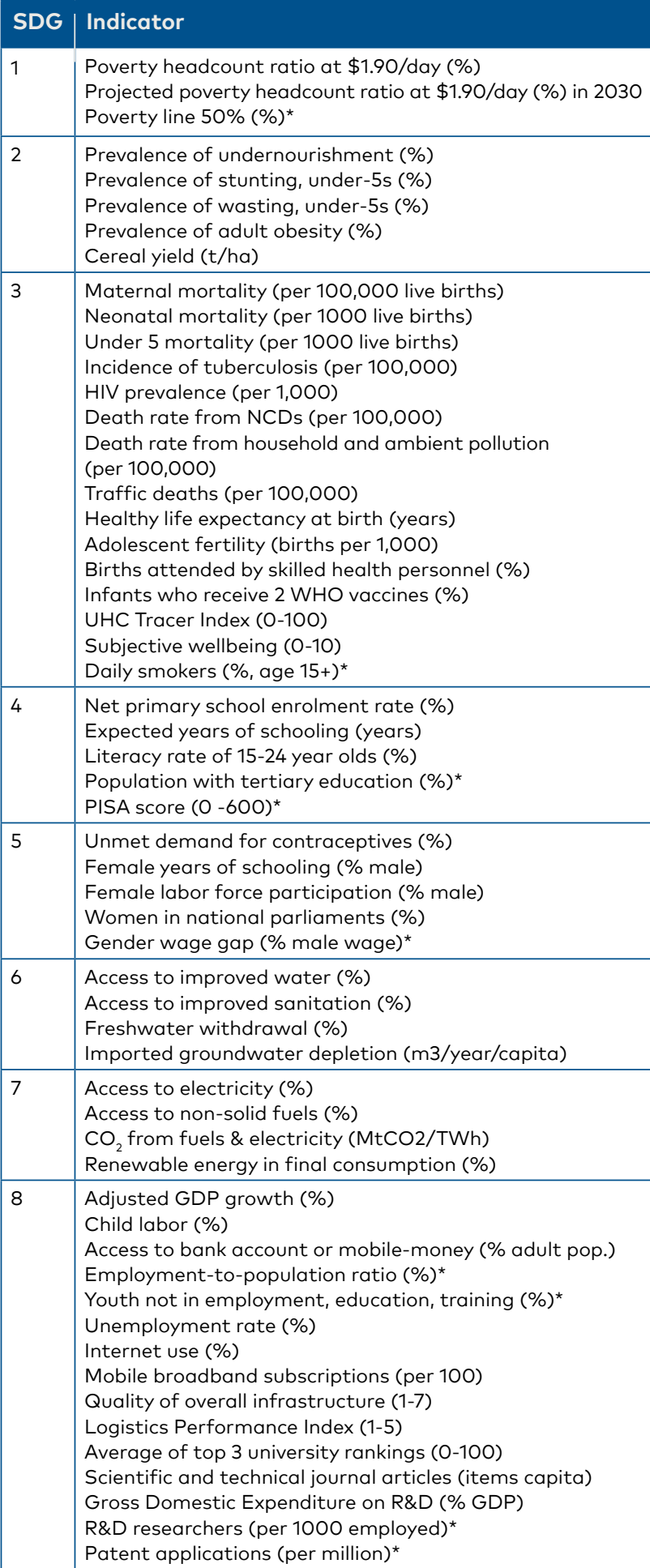

\section{SDG | Indicator}

\begin{tabular}{|c|c|}
\hline 10 & $\begin{array}{l}\text { Gini index }(0-100) \\
\text { Palma ratio* } \\
\text { PISA Social Justice Index }(0-10)^{\star}\end{array}$ \\
\hline 11 & $\begin{array}{l}\text { PM2.5 in urban areas }(\mu \mathrm{g} / \mathrm{m} 3) \\
\text { Improved water source, piped (\%) } \\
\text { Rent burden (\% disposable income) }\end{array}$ \\
\hline 12 & $\begin{array}{l}\text { E-waste (kg/capita) } \\
\text { Wastewater treated (\%) } \\
\text { Production-based } \mathrm{SO}_{2} \text { emissions (kg/capita) } \\
\text { Net imported } \mathrm{SO}_{2} \text { emissions (kg/capita) } \\
\text { Nitrogen production footprint (kg/capita) } \\
\text { Net imported emissions of reactive nitrogen (kg/capita) } \\
\text { Non-recycled municipal solid waste (kg/person/year)* } \\
\text { Municipal solid waste (kg/person/year) }\end{array}$ \\
\hline 13 & $\begin{array}{l}\mathrm{CO}_{2} \text { emissions from energy }\left(\mathrm{tCO}_{2} / \text { capita) }\right. \\
\text { Imported } \mathrm{CO}_{2} \text { emissions, tech-adjusted }\left(\mathrm{tCO}_{2} / \text { capita) }\right. \\
\text { Climate change vulnerability }(\mathrm{O}-1) \\
\text { Effective Carbon Rate }\left(€ / \mathrm{tCO}_{2}\right)^{\star}\end{array}$ \\
\hline 14 & $\begin{array}{l}\text { Marine sites, mean protected area (\%) } \\
\text { Ocean Health Index - Biodiversity (O-100) } \\
\text { Ocean Health Index - Clean waters (0-100) } \\
\text { Ocean Healh Index - Fisheries (O-100) } \\
\text { Fish stocks overexploited or collapsed (\%) }\end{array}$ \\
\hline 15 & $\begin{array}{l}\text { Terrestrial sites, mean protected (\%) } \\
\text { Freshwater sites, mean protected area (\%) } \\
\text { Red List Index of species survival (0-1) } \\
\text { Annual change in forest area (\%) } \\
\text { Imported biodiversity impacts (species/million people) }\end{array}$ \\
\hline 16 & $\begin{array}{l}\text { Homicides (per } 100,000 \text { ) } \\
\text { Prison population (per 100,000) } \\
\text { Feel safe walking at night (\%) } \\
\text { Government efficiency (1-7) } \\
\text { Property rights (1-7) } \\
\text { Registered births (\%) } \\
\text { Corruption Perception Index (0-100) } \\
\text { Slavery Score (0-100) } \\
\text { Conventional weapons exports (US } \$ \text { m per } 100,000 \\
\text { people) }\end{array}$ \\
\hline 17 & $\begin{array}{l}\text { Health \& Education spending ( } \% \text { GDP) } \\
\text { Official development assistance ( } \% \text { GNI)* } \\
\text { Tax revenue (\% GDP) } \\
\text { Tax Haven Score (best } 0-5 \text { worst) }\end{array}$ \\
\hline
\end{tabular}




\section{Nordic Council of Ministers}

The report Baltic 2030: Bumps on the Road provides an overview of the 2030 Agenda implementation in the Baltic Sea Region, aimed at informing strategy and prioritisation discussions for national and regional collaboration. For each of the region's eleven countries, performance on the Sustainable Development Goals (SDGs) is examined and five selected SDGs are discussed at the indicator level. Based on this analysis, the authors recommend seven avenues for action where greater collaboration in the region can support SDG achievement.

The report was commissioned by the Council of the Baltic Sea States (CBSS) and is jointly published by CBSS and the Nordic Council of Ministers (NCM). It was drafted by the advisory firm Nordic Sustainability and follows the previous Bumps on the Road to 2030 report published by the NCM in 2017. 